\title{
BIODEGRADABILIDADE ANAERÓBIA DE EFLUENTE DO PROCESSAMENTO DA ACEROLA VERDE
}

\section{ANAEROBIC BIODEGRADABILITY OF EFFLUENT FROM GREEN ACEROLA PROCESSING}

Andreza Carla Lopes André

Graduanda em Engenharia Agrícola e Ambiental, Universidade Federal do Vale do São Francisco. Bolsista PET Saneamento Ambiental. (andreza carlalopes@hotmail.com).

\section{Rodrigo Torres Silva}

Graduando em Engenharia Agrícola e Ambiental, Universidade Federal do Vale do São Francisco. Bolsista PET Saneamento Ambiental. (rodxtorres@hotmail.com).

\section{Kessia Caroline Dantas da Silva}

Graduanda em Engenharia Agrícola e Ambiental, Universidade Federal do Vale do São Francisco. Bolsista PET Saneamento Ambiental. (kessia155@hotmail.com).

\section{Paula Tereza de Souza e Silva}

Doutora em Química, Universidade Federal de Pernambuco. Embrapa Semiárido. (paula.silva@embrapa.br)

\section{Miriam Cleide Cavalcante de Amorim}

Doutora em Engenharia Química, Universidade Federal de Pernambuco. Universidade Federal do Vale do São Francisco / Colegiado de Engenharia Agrícola e Ambiental. (miriam.cleide@univasf.edu.br).

\section{Resumo}

A agroindústria aceroleira gera efluentes com elevada carga orgânica, sendo, portanto, um poluidor em potencial. O objetivo deste estudo é avaliar a biodegradabilidade anaeróbia desse efluente em termos da demanda química de oxigênio e produção de metano. Os ensaios tiveram duração de $288 \mathrm{~h}$ e foram realizados por meio de frascos-reatores, utilizando tratamentos com diferentes concentrações de $\mathrm{DQO}_{(4 \mathrm{~g} \mathrm{O}} \mathrm{O}^{-1}$, $8 \mathrm{~g}$ $\mathrm{O}_{2} . \mathrm{L}^{-1}$ e $\left.12 \mathrm{~g} \mathrm{O}_{2} . \mathrm{L}^{-1}\right)$ e uma de biomassa de lodo anaeróbio $\left(5 \mathrm{~g} . \mathrm{L}^{-1}\right)$. Efetuaram-se análises de $\mathrm{DQO}$, ácidos graxos voláteis, $\mathrm{pH}$ e alcalinidade. Todos os tratamentos proporcionaram remoções de DQO acima de $65 \%$. Houve relação entre a concentração de DQO aplicada e as condições ambientais dos frascos-reatores, em que quanto maior a DQO, mais inadequadas tornaram-se as condições ambientais. O efluente com $4 \mathrm{~g} \mathrm{O}_{2} \mathrm{~L}^{-1}$ obteve o maior rendimento de metano (42,5\%), bem como a maior taxa de produção de metano (102 mL de $\mathrm{CH}_{4} \cdot \mathrm{g}^{-1}$ de DQOrem). Os ensaios de biodegradabilidade mostraram que o efluente estudado apresentou boa degradabilidade anaeróbia, principalmente para a remoção de carga orgânica.

Palavras-Chave: acerola, degradabilidade, metano.

\section{Abstract}

The acerola agro-industry generates effluents with elevated organic load, therefore, it is a potential polluter. The objective of this study is to evaluate the anaerobic biodegradability of this effluent in terms of chemical oxygen demand and methane production. The assays lasted 288 hours and were performed by means of reactor flasks using treatments with different concentrations of COD $\left(4 \mathrm{~g} \mathrm{O}_{2} \mathrm{~L}^{-1}, 8 \mathrm{~g} \mathrm{O}_{2} . \mathrm{L}^{-1}\right.$ and $\left.12 \mathrm{~g} \mathrm{O}_{2} . \mathrm{L}^{-1}\right)$ and one of anaerobic sludge biomass $\left(5 \mathrm{gL}^{-1}\right)$. Analyzes of COD, volatile fatty acids, $\mathrm{pH}$ and alkalinity were performed. All treatments provided removals of COD above $65 \%$. There was a relation between the COD concentration applied and the environmental conditions of the flasks, where the higher the COD, the more unsuitable the environmental conditions became. The effluent with $4 \mathrm{~g} \mathrm{O}_{2} . \mathrm{L}^{-1}$ obtained the greater methane yield (42.5\%) as well as the highest methane production rate (102 $\mathrm{mL} \mathrm{CH}_{4} \mathrm{~g}^{-1}$ of CODrem). The biodegradability tests showed that the studied effluent presented good anaerobic degradability mainly for the removal of organic load.

Keywords: acerola, degradability, methane. 


\section{INTRODUÇÃO}

A acerola (Malphigia Emarginata DC.), também conhecida como "Cereja das Antilhas" por ser originária do mar das Antilhas, norte da América do Sul e América Central, foi introduzida no Brasil, primeiramente, no Estado de Pernambuco pela Universidade Federal Rural de Pernambuco, em 1955, através de sementes oriundas de Porto Rico. Em função de suas características e do seu bom desenvolvimento em clima tropical, a acerola rapidamente foi disseminada em quase todo o território nacional (CARVALHO et al., 2000).

No Brasil, a fruticultura irrigada das frutíferas tropicais é destaque em pelo menos 14 polos de irrigação do Nordeste, onde a produtividade é garantida por seu solo fértil e ótimas condições climáticas da região, o que permite a produção de frutas durante quase 0 ano inteiro (LACERDA; LACERDA, 2004). De acordo com os dados do IBGE (2017), no Brasil, os estados com maior produção de acerola são Rondônia, Pernambuco, Ceará, Sergipe e Paraíba, com 53,24\%, 15,43\%, $5,57 \%, 4,33 \%$ e $3,57 \%$, respectivamente. Em Pernambuco, Petrolina destaca-se com $71,29 \%$ da produção.

A aceroleira é responsável pela produção de frutos ricos em ácido ascórbico (vitamina C) e compostos com ação antioxidante (antocianinas e caratenóides). Segundo Calgaro e Braga (2012), a depender da variedade, o teor de ácido ascórbico desse fruto pode chegar a $5.000 \mathrm{mg} .100 \mathrm{~g}^{-1}$ de polpa, teor 100 vezes superior ao da laranja e 10 vezes superior ao da goiaba. Estas são características que atraem fruticultores que visam comercializar o produto, além do seu fácil cultivo, sabor e aroma agradáveis e elevada capacidade de aproveitamento industrial da fruta, o que promove a elaboração de vários produtos alimentícios, tais como sucos, compotas, geleias, refrigerantes, entre outros. É, também, utilizada no mercado de cosméticos, como na composição de shampoos e sabonetes, e na indústria farmacêutica para produção de suplementos alimentares e cápsulas de vitamina C (SOBRINHO, 2014; GODOY et al., 2008; SOUZA et al., 2017).

Por ser classificada como um fruto climatérico, isto é, seu processo de maturação pode se dar ainda na planta ou mesmo após a colheita, a acerola possui uma alta perecibilidade, o que torna sua comercialização, por vezes, difícil e limitada. Diante disso, o processamento da acerola torna-se uma alternativa para a manutenção da cadeia produtiva do fruto (CARRINGTON; KING, 2002; GODOY et al., 2008). No entanto, segundo Lousada Júnior et al. (2005), o processamento de frutas é responsável pela geração de subprodutos e, consequentemente, de resíduos e efluentes agroindustriais que podem representar uma fonte de poluição ambiental.

O efluente oriundo do processamento de acerola apresenta elevada carga orgânica e, por consequência, grande potencial poluidor quando disposto no meio ambiente sem um tratamento prévio. Em virtude disso, de acordo com Jerônimo (2012), a aplicação de um tratamento biológico pode ser uma alternativa viável e eficaz, com a capacidade de proporcionar ainda um reaproveitamento energético, tratando-se de digestão anaeróbia.

São diversas as vantagens apresentadas por Weber (2006) sobre processos biológicos anaeróbios em comparação aos aeróbios, tais como a baixa produção de lodo, menor utilização de energia, geração de metano (fonte de energia renovável), além da possibilidade de aplicação em locais que não possuem grande disponibilidade de espaço. Estudos realizados por Montefusco et al. (2017), utilizando efluente oriundo da agroindústria aceroleira, estimam que a aplicação de um tratamento anaeróbio é capaz de gerar cerca de $81,09 \mathrm{~m}^{3} \cdot \mathrm{d}^{-1}$ de metano.

O processo de digestão anaeróbia realizado pelos microrganismos envolve processos metabólicos complexos e é efetuado por pelo menos três grupos de microrganismos que atuam simultaneamente, são eles, bactérias acidogênicas, acetogênicas e arqueas metanogênicas. As bactérias acidogênicas são responsáveis por converter, por hidrólise e fermentação, compostos orgânicos complexos em compostos orgânicos mais simples, principalmente ácidos orgânicos, hidrogênio e dióxido de carbono. As bactérias acetogênicas, por sua vez, convertem compostos orgânicos intermediários em acetato, hidrogênio e dióxido de carbono, enquanto as arqueas metanogênicas são responsáveis por converter o acetato e hidrogênio produzidos em biogás (CHERNICHARO, 2007).

$\mathrm{Na}$ literatura, são apresentados diferentes métodos para determinação da biodegradabilidade de diversos efluentes (BERTOLINO; CARVALHO; AQUINO, 2008; AMORIM et al., 2013), sendo estes, segundo Amaral et al. (2008), baseados no monitoramento da formação de um ou mais 
produtos envolvidos na reação biológica, a exemplo de ensaios que se baseiam na medição da produção acumulada de metano ou no monitoramento da depleção do substrato.

Há, ainda, um conjunto de condições ambientais importantes para auxiliar a avaliação do processo de digestão anaeróbia, tais como potencial hidrogeniônico $(\mathrm{pH})$, ácidos graxos voláteis (AGV) e alcalinidade total (AT) (CHERNICHARO, 2007). Para Costa (2009), tais condições interagem entre si e determinam a estabilidade do processo de degradação anaeróbia, já que a alcalinidade do sistema reflete sua capacidade de neutralizar ácidos e tamponar o sistema quando houver acúmulo de AGV devido a algum distúrbio.

De acordo com Corrêa et al. (2017) e Magalhães et al. (2018), as características físicoquímicas do fruto da acerola diferem em função do seu estádio de maturação, sendo que a acerola verde apresenta maiores teores de sacarose. Esses autores identificaram que 0 amadurecimento da acerola verde produz um acréscimo da sacarose de $1,87 \mathrm{mg} \cdot \mathrm{g}^{-1}$ (verde) para $3,06 \mathrm{mg} \cdot \mathrm{g}^{-1}$ (totalmente madura). Assim, tendo a digestão anaeróbia como um de seus processos a hidrólise de carboidratos e açúcares, o estádio do fruto provavelmente influenciará a anaerobiose.

O presente estudo tem como objetivo avaliar a biodegradabilidade anaeróbia do efluente produzido no processamento da acerola verde.

\section{METODOLOGIA}

\section{- Local do estudo e caracterização do efluente}

A pesquisa foi desenvolvida utilizando efluente do processamento de acerola verde proveniente da NIAGRO (Nichirei do Brasil Agrícola Ltda, agroindústria localizada no distrito industrial de Petrolina-PE) e o inóculo de lodo anaeróbio de reator UASB (Upflow Anaerobic Sludge Blanket), tratando esgotos domésticos, na Companhia Pernambucana de Saneamento (COMPESA) em Petrolina-PE. O efluente e o lodo foram coletados em galões e encaminhados ao Laboratório de Engenharia Ambiental - LEA da Universidade Federal do Vale do São Francisco UNIVASF, Campus Juazeiro-BA, onde foram acondicionados em freezer a $4^{\circ} \mathrm{C}$. Todas as etapas do processamento da acerola verde estão compreendidas no fluxograma disposto na Figura 1.

O efluente estudado é derivado da etapa que compreende a Ultrafiltração (UF), pois é nesta que se encontra a maior carga orgânica. Os parâmetros utilizados para a caracterização do efluente bruto do processamento de acerola verde, bem como seus respectivos métodos de determinação, encontram-se na Tabela 1.

\section{- Ensaio de biodegradabilidade anaeróbia}

O ensaio da biodegradabilidade anaeróbia foi conduzido conforme metodologia dos frascos sacrifício adotada por Amorim et al. (2013), o qual consiste em sacrificar um conjunto de frascos reatores em triplicatas para análises do efluente no decorrer do tempo de degradação. Foram avaliadas três concentrações de DQO $\left(\mathrm{T}_{1}=4 \mathrm{~g} \mathrm{O}_{2}\right.$. $\mathrm{L}^{-1}, \mathrm{~T}_{2}=8 \mathrm{~g} \mathrm{O}_{2}$. $\mathrm{L}^{-1}$ e $\mathrm{T}_{3}=12 \mathrm{~g} \mathrm{O}_{2}$. $\left.\mathrm{L}^{-1}\right)$, sendo tais valores estabelecidos com a finalidade de obter dados para aplicação em escala real. Utilizou-se lodo na concentração de $5 \mathrm{~g}$ de STV.L-1 , conforme estudo realizado por Bertolino; Carvalho e Aquino (2008). Já as concentrações de macro e micro nutrientes mantidas em cada frasco reator (por litro) foram determinadas em função das necessidades nutricionais dos microrganismos do lodo, recomendadas por Florêncio (1994), cujos nutrientes e suas respectivas quantidades estão dispostas no Quadro 1.

Tabela 1: Caracterização do efluente bruto de acerola verde.

\begin{tabular}{ccc}
\hline Parâmetro & Método de determinação & Quantidade \\
\hline $\begin{array}{c}\text { Demanda Química de } \\
\text { Oxigênio (DQO) }\end{array}$ & Colorimétrico & $88,72 \mathrm{~g} \mathrm{O}_{2} \mathrm{~L}^{-1}$ \\
Proteínas & Espectrofotométrico & $66,94 \mathrm{~g} . \mathrm{L}^{-1}$ \\
Carboidratos & Espectrofotométrico & $54,95 \mathrm{~g} . \mathrm{L}^{-1}$ \\
Fósforo & Colorimétrico & $1,9 \mathrm{~g} . \mathrm{L}^{-1}$ \\
\hline
\end{tabular}

Fonte: Autores. 
Figura 1: Fluxograma das etapas que compreendem o processamento da acerola verde

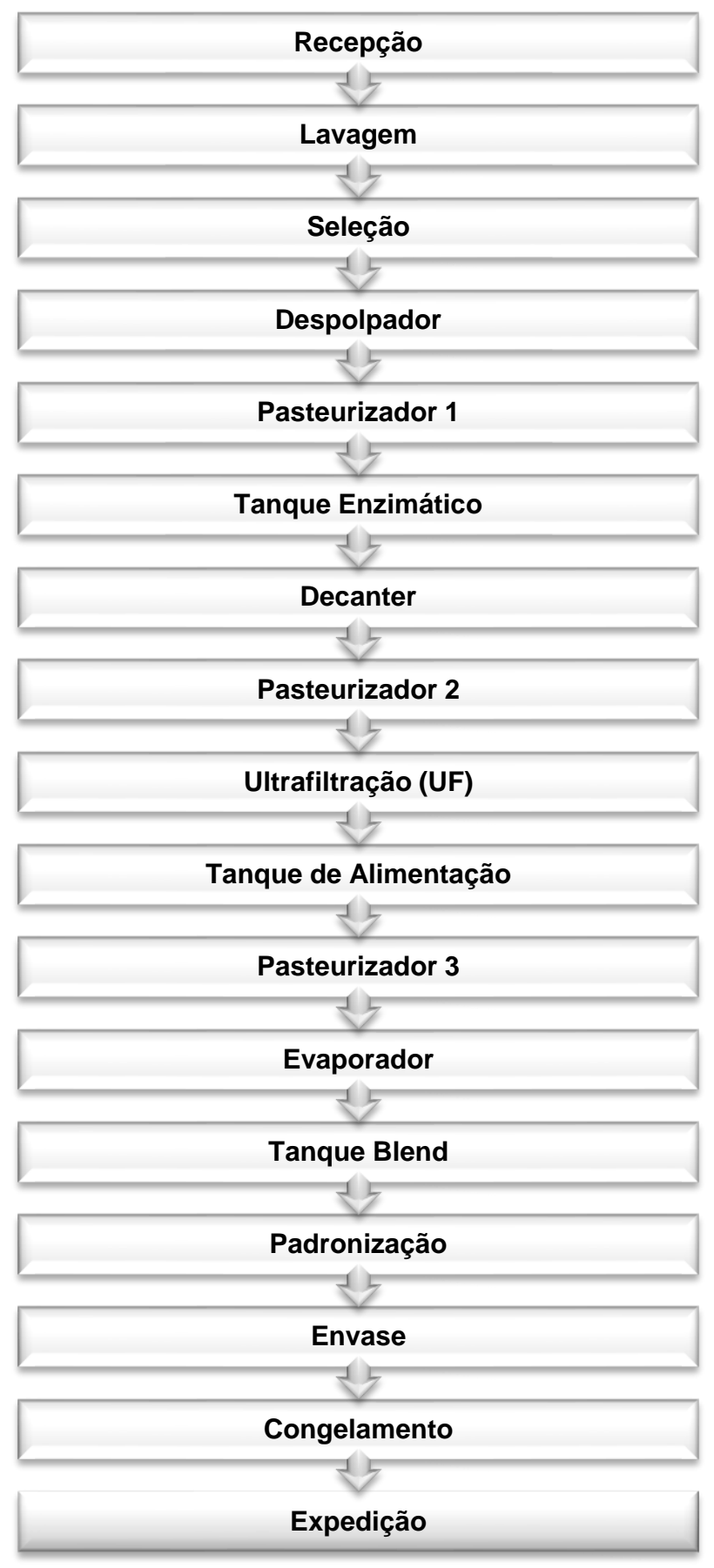

Fonte: Autores.

A partir das concentrações estabelecidas, foi possível determinar os volumes de inóculo e de efluente a serem incubados. Os frascos-reatores foram montados em triplicata para os três tratamentos, com um conjunto de triplicatas destinado ao branco contendo apenas inóculo, água e solução nutriente (Tabela 2).

Os frascos-reatores (81 ao total) apresentavam volume útil de $0,092 \mathrm{~L}$ e head space de 0,026 L, conforme recomendado por Aquino et al. (2007). Os ensaios tiveram um tempo de degradação de 288h, seguindo estudos realizados por Amorim et al. (2013), com os três tratamentos em triplicata, em que a cada 48 horas eram sacrificados três frascos-reatores de cada tratamento para realização das análises. 
Quadro 1: Nutrientes utilizados para a suplementação nutricional e suas respectivas quantidades.

\begin{tabular}{|c|c|}
\hline Nutriente & Quantidade \\
\hline $\mathrm{NH}_{4} \mathrm{Cl}$ & $56,00 \mathrm{mg}$ \\
\hline $\mathrm{K}_{2} \mathrm{HPO}_{4}$ & $50,40 \mathrm{mg}$ \\
\hline $\mathrm{MgSO}_{4 .} .7 \mathrm{H}_{2} \mathrm{O}$ & $20,00 \mathrm{mg}$ \\
\hline $\mathrm{CaCl}_{2}$ & $1,40 \mathrm{mg}$ \\
\hline $\mathrm{NaHCO}_{3}$ & $80,00 \mathrm{mg}$ \\
\hline $\mathrm{FeCl}_{2} .4 \mathrm{H}_{2} \mathrm{O}$ & $400,00 \mathrm{mg}$ \\
\hline $\mathrm{ZnCl}_{2}$ & $0,010 \mathrm{mg}$ \\
\hline $\mathrm{MnCl}_{2}$ & $0,100 \mathrm{mg}$ \\
\hline $\mathrm{NiCl}_{2}$ & $0,028 \mathrm{mg}$ \\
\hline $\mathrm{H}_{3} \mathrm{BO}_{3}$ & $0,010 \mathrm{mg}$ \\
\hline $\mathrm{CuCl}_{2} .2 \mathrm{H}_{2} \mathrm{O}$ & $0,0076 \mathrm{mg}$ \\
\hline $\mathrm{CoCl}_{2} .6 \mathrm{H}_{2} \mathrm{O}$ & $400,00 \mathrm{mg}$ \\
\hline $\mathrm{AlCl}_{3} .6 \mathrm{H}_{2} \mathrm{O}$ & $0,018 \mathrm{mg}$ \\
\hline$\left(\mathrm{NH}_{4}\right) 6 \mathrm{Mo} 7 \mathrm{O}_{24 .} 4 \mathrm{H}_{2} \mathrm{O}$ & $0,010 \mathrm{mg}$ \\
\hline EDTA & $200,00 \mathrm{mg}$ \\
\hline $\mathrm{HCl}$ & $200,00 \mu \mathrm{L} . \mathrm{L}^{-1}$ \\
\hline
\end{tabular}

Fonte: Autores.

Tabela 2: Concentrações do inóculo e de efluente e volumes de inóculo, efluente, solução nutriente e água utilizados na montagem dos frascos-reatores.

\begin{tabular}{|c|c|c|c|c|c|c|}
\hline $\begin{array}{l}\text { Frascos- } \\
\text { Reatores }\end{array}$ & Cl (gSTV.L-1) & CE (gDQO.L-1) & VI (mL) & VE (mL) & VSN (mL) & VA (mL) \\
\hline Branco & 5,0 & - & 4,0 & - & 19,0 & 69,0 \\
\hline$\overline{T_{1}}$ & 5,0 & 4,0 & 4,0 & 4,0 & 19,0 & 65,0 \\
\hline$T_{2}$ & 5,0 & 8,0 & 4,0 & 9,0 & 19,0 & 60,0 \\
\hline $\mathrm{T}_{3}$ & 5,0 & 12,0 & 4,0 & 13,0 & 19,0 & 56,0 \\
\hline
\end{tabular}

Cl: Concentração do inóculo; CE: Concentração do Efluente; VI: Volume de Inóculo; VE: Volume de Efluente; VSN: Volume de Solução nutritiva; VA: Volume de água.

Fonte: Autores.

$\mathrm{O} \mathrm{pH}$ em todos os tratamentos foi aferido no início dos ensaios (dia zero) para garantir valores próximos à neutralidade, condição ideal para as bactérias constituintes do lodo (CHERNICHARO, 2007). Em seguida, os frascos-reatores foram vedados com tampas de borracha e lacres de alumínio com o auxílio de um alicate recravador. $\mathrm{Na}$ tampa de borracha, foi inserida uma agulha acoplada a uma seringa de $10 \mathrm{~mL}$ para a medição e coleta do biogás (Figura 2). Os frascos foram incubados em estufa a, aproximadamente, $30 \pm$ $2^{\circ} \mathrm{C}$, temperatura ideal para as bactérias constituintes do lodo (METCALF; EDDY, 2003).

Análises de demanda química de oxigênio, $\mathrm{pH}$, alcalinidade total e ácidos graxos voláteis foram realizadas no início do experimento (dia 
zero), após $24 \mathrm{~h}$ e $48 \mathrm{~h}$, e posteriormente efetuadas a cada 48 horas até a $288^{\text {a }}$ hora, perfazendo um total de oito amostragens. A biodegradabilidade anaeróbia do efluente estudado foi avaliada em termos de demanda química de oxigênio e da produção de metano. Avaliou-se a estabilidade do processo de degradação por meio das condições ambientais ( $\mathrm{pH}$ e relação AGV/AT).

Um conjunto de frascos-reatores em triplicata foi destinado à análise da composição do biogás, com duas seringas conectadas aos frascosreatores por meio de duas válvulas de três vias que permitiam a coleta do biogás. O biogás era inserido em frascos coletores de gás com borracha nitrílica e, posteriormente, enviados ao Laboratório de Química Ambiental da EMBRAPA Semiárido. A análise da composição do biogás foi feita por meio de um cromatógrafo gasoso da marca agilent, modelo 7890A com detector do tipo FID equipado com metanador. A coluna utilizada foi a agilent Hayesep Q80/100; como gás de arraste, usou-se

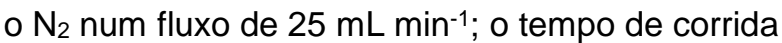
foi de 11 minutos e a temperatura do detector e a do forno foram $300^{\circ} \mathrm{C}$ e $60^{\circ} \mathrm{C}$, respectivamente. Para os cálculos das concentrações de dióxido de carbono e metano, foram construídas duas curvas de calibração, uma para o $\operatorname{CO} 2(250,500$ e 1000 ppm) e outra para o $\mathrm{CH} 4(0,5,1$ e 3 ppm). A amostragem foi realizada a cada 48 horas, perfazendo um total de seis (6) campanhas e 54 amostras.

O volume de metano produzido durante $\mathrm{O}$ experimento $\left(\mathrm{V}_{\mathrm{CH}}\right)$ foi medido com base na composição do biogás. Durante os ensaios, foram calculados o rendimento $\left(\mathrm{R}_{\mathrm{CH}} 4\right)$ do metano em relação ao metano teórico ( $\mathrm{VT}_{\mathrm{CH} 4}$ ), segundo Metcalf e Eddy (2003), para uma remoção teórica de $60 \%$ de DQO (correspondente à DQO removida convertida em metano, a $30 \stackrel{\circ}{\circ}$ e 1 atm), bem como a taxa de produção de metano $(\mathrm{mL}$ de $\mathrm{CH}_{4} \cdot \mathrm{g}^{-1}$ de DQOrem).

\section{Figura 2: Frascos-reatores utilizados nos ensaios de biodegradabilidade.}

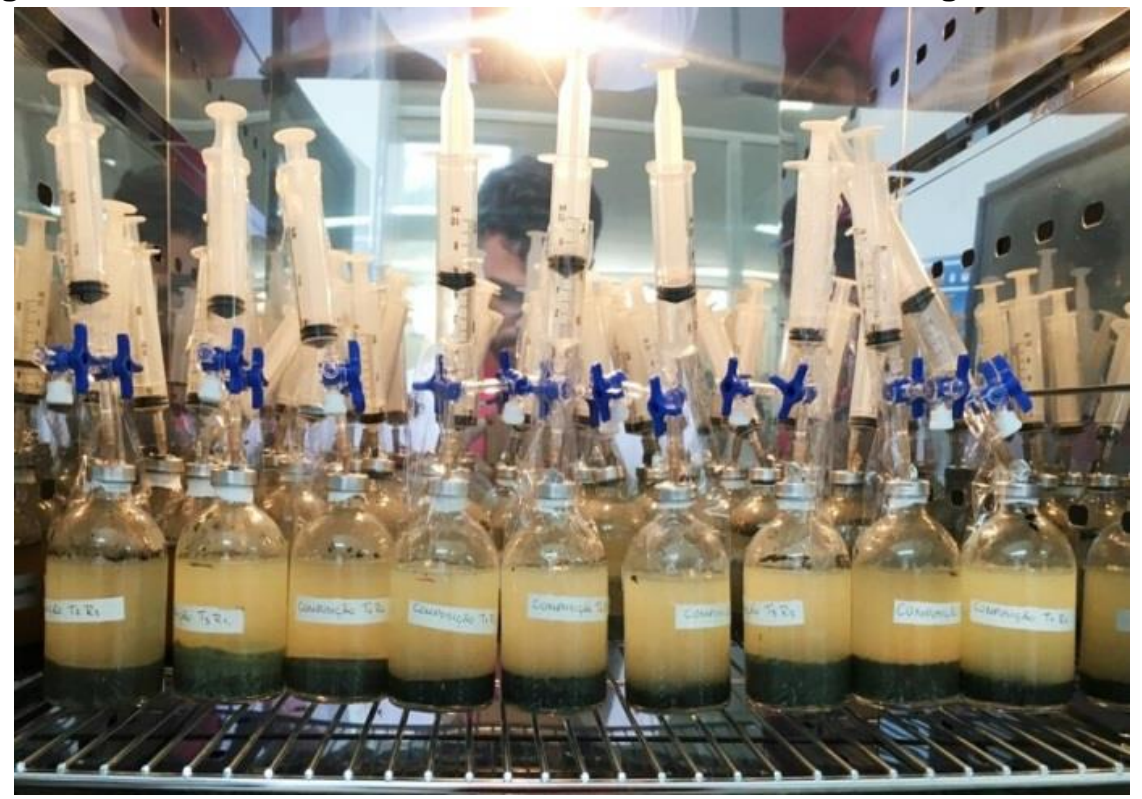

Fonte: Autores.

\section{RESULTADOS E DISCUSSÃO}

\section{- Relação AGV/AT e pH}

A Figura 3 apresenta a relação AGV/AT e o pH de todos os tratamentos ao longo do tempo de experimento. No início da operação (Oh), todos os tratamentos apresentaram relação AGV/AT adequada, conforme estabelecido por Chernicharo (2007), cujos valores da relação devem ser inferiores a 0,3 . Com exceção de $T_{1}$ às $24 h$, todos os tratamentos a partir desse período apresentaram valores elevados desta relação, em que a concentração de ácidos superou a alcalinidade, fato que, segundo Chernicharo (2007), sugere condição instável do sistema a partir desse ponto e provável incapacidade de neutralização dos ácidos.

$\mathrm{O}_{3}$ foi o que apresentou maior valor da relação AGV/AT em todas as análises, devido à elevada acumulação de ácidos e à baixa capacidade de tamponamento do sistema, fatos decorrentes da aplicação de uma carga orgânica maior nesse tratamento. Em virtude da alta relação 
AGV/AT, o pH desse tratamento foi o mais baixo em todos os momentos (Figura 3). Já $\mathrm{T}_{1}$ apresentou os menores valores da relação AGV/AT, indicando melhor capacidade de tamponamento em relação aos outros tratamentos, fato que pôde ser comprovado pela baixa variação de $\mathrm{pH}$ para esse tratamento em relação aos demais, se mantendo em todos os momentos acima de 6,2.
Os resultados obtidos para a relação AGV/AT em todos os tratamentos se relacionam diretamente com a DQO aplicada em cada tratamento, sendo que, nos tratamentos com maior concentração de DQO, as relações AGV/AT também foram as maiores ao longo do tempo. Resultados estes que implicaram em variações no $\mathrm{pH}$ e consequente instabilidade do processo de degradação anaeróbia.

Figura 3: pH e relação AGV/AT ao longo do tempo de biodegradação.

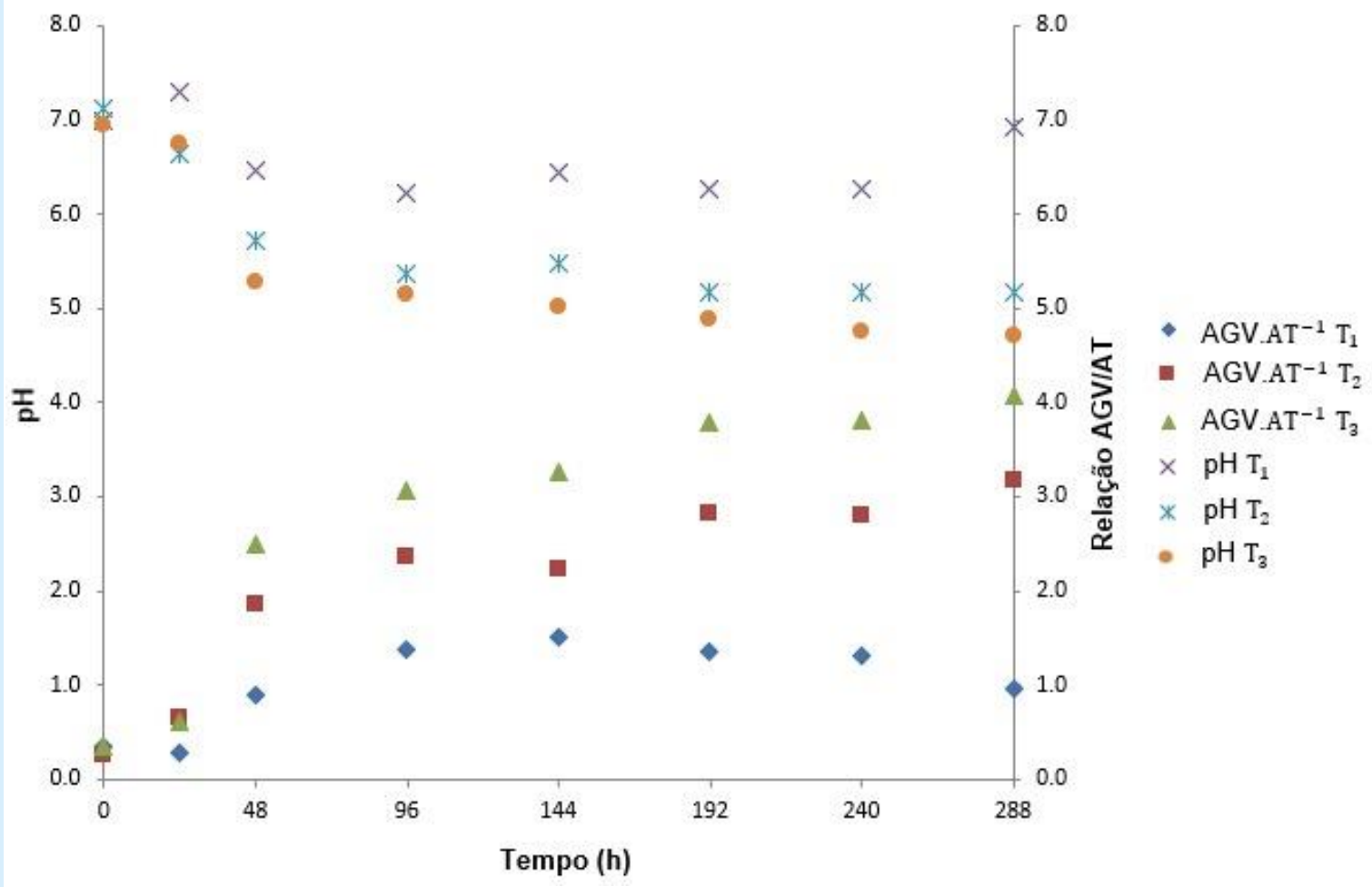

Fonte: Autores.

\section{- Matéria orgânica removida}

A Figura 4 apresenta os percentuais de remoção da matéria orgânica dos tratamentos em relação ao dia zero. Observa-se que não houve diferença entre $T_{1}$ e $T_{2}$, pois ambos apresentaram redução progressiva da DQO até $192 \mathrm{~h}$ de $89 \%$ e $90 \%$, respectivamente. Os resultados encontrados corroboram outros estudos com efluentes agroindustriais, como o de Amorim et al. (2014) que, em pesquisa semelhante com manipueira

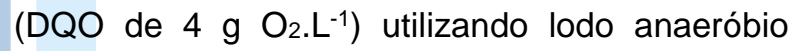
como inóculo (4 g. $\left.\mathrm{L}^{-1}\right)$, obtiveram $89 \%$ de eficiência de remoção da DQO. Já Barros (2017), em regime de batelada na partida de reator UASB utilizando efluente da agroindústria aceroleira ( 3 g.L-1 $)$, obteve remoções de DQO entre 70 e $90 \%$.

No entanto, o $T_{1}$ apresentou as melhores condições ambientais, o que leva a crer que uma quantidade considerável de matéria orgânica presente neste tratamento pode ter sido totalmente estabilizada em até $192 \mathrm{~h}$, restando apenas a fração inorgânica e, porventura, a fração de matéria orgânica recalcitrante, pois após esse período a remoção da DQO se manteve constante. Além disso, como não houve diferença em termos de remoção da DQO entre os tratamentos, boa parte da matéria orgânica presente em $\mathrm{T}_{2}$ também pode ter sido totalmente estabilizada até as $192 \mathrm{~h}$, apesar das condições ambientais desse tratamento não serem adequadas, apresentando valores elevados da relação AGV/AT $(2,83)$ e pH mais ácido $(5,17)$. Tais condições, de acordo com Chernicharo (2007), provocam a instabilidade do processo de degradação anaeróbica em virtude de um desequilíbrio entre as populações bacterianas envolvidas no processo.

Já no $T_{3}$, a remoção da $D Q O$ foi progressiva até $96 \mathrm{~h}(79 \%)$, e a partir desse momento a 
remoção diminuiu, fato que pode ser explicado pelas condições ambientais adversas desse tratamento - que apresentou alta relação AGV/AT $(4,07)$ e $\mathrm{pH}$ abaixo de 5 - e pela maior concentração de DQO aplicada (12 $\left.\mathrm{g} \mathrm{O}_{2} \cdot \mathrm{L}^{-1}\right)$.

Observa-se ainda que, para $\mathrm{T}_{1} \mathrm{e} \mathrm{T}_{2}$, as maiores taxas de remoção da DQO se deram em torno de 192h, o que indica que a biodegradabilidade em sistema piloto pode ser trabalhada com um tempo de detenção hidráulica próximo a esse valor. Também, todos os tratamentos apresentaram remoções da matéria orgânica acima de $65 \%$, o que sugere que o efluente tem potencial para ser tratado biologicamente; e, se forem fornecidas condições ambientais adequadas para os microrganismos degradadores, os resultados obtidos para todos os tratamentos podem vir a apresentar maiores eficiências de remoção.

\section{- Produção de metano e rendimento e taxa de produção}

$\mathrm{Na}$ Figura 5, observa-se a produção acumulada de metano ao longo do ensaio de biodegradabilidade. Todos os tratamentos atingiram as maiores produções de metano após $288 \mathrm{~h}$, quando $\mathrm{T}_{1}$ produziu $59,9 \mathrm{~mL}, \mathrm{~T}_{2} 67,3 \mathrm{~mL}$ e $\mathrm{T}_{3}$ $81,0 \mathrm{~mL}$. Os volumes nos tratamentos foram tanto maiores quanto maiores as concentrações de DQO e associados com os percentuais de remoções de DQO (DQOrem). Percebe-se, portanto, que houve relação entre a concentração de DQO do efluente aplicada e o volume de metano produzido, sendo que quanto maior a carga orgânica aplicada, maior a produção de metano.

Embora $\mathrm{T}_{1}$ tenha apresentado a menor produção de metano em relação aos demais tratamentos, este apresentou o maior rendimento de metano em relação ao metano teórico $(42,5 \%)$ após $288 \mathrm{~h}$, bem como a maior taxa de produção de metano (102 $\mathrm{mL}$ de $\mathrm{CH}_{4} \cdot \mathrm{g}^{-1}$ de DQOrem), conforme Tabela 3 . Isto pode ter ocorrido em função das menores concentrações de AGV do efluente nesse tratamento (2,06 g HAc. $\left.\mathrm{L}^{-1}\right)$, proporcionando a menor relação $\operatorname{AGV/AT}(0,96)$ e o maior percentual de remoção de DQO em relação aos demais tratamentos. Esses resultados corroboram outros estudos realizados com efluentes agroindustriais. Çelik e Demirer (2015), avaliando o potencial de produção de biogás a partir de efluente (bruto e tratado termicamente) oriundo do processamento de pistache, obtiveram uma taxa de produção de metano entre $42,2-73,4$ $\mathrm{mL}$ de $\mathrm{CH}_{4} \cdot \mathrm{g}^{-1}$ de $\mathrm{DQO}_{\text {rem }}$ para o efluente bruto e $78,5-213,4 \mathrm{~mL}$ de $\mathrm{CH}_{4} \cdot \mathrm{g}^{-1}$ de DQOrem para o efluente que recebeu tratamento térmico.

Figura 4: Percentual de remoção da DQO dos tratamentos.

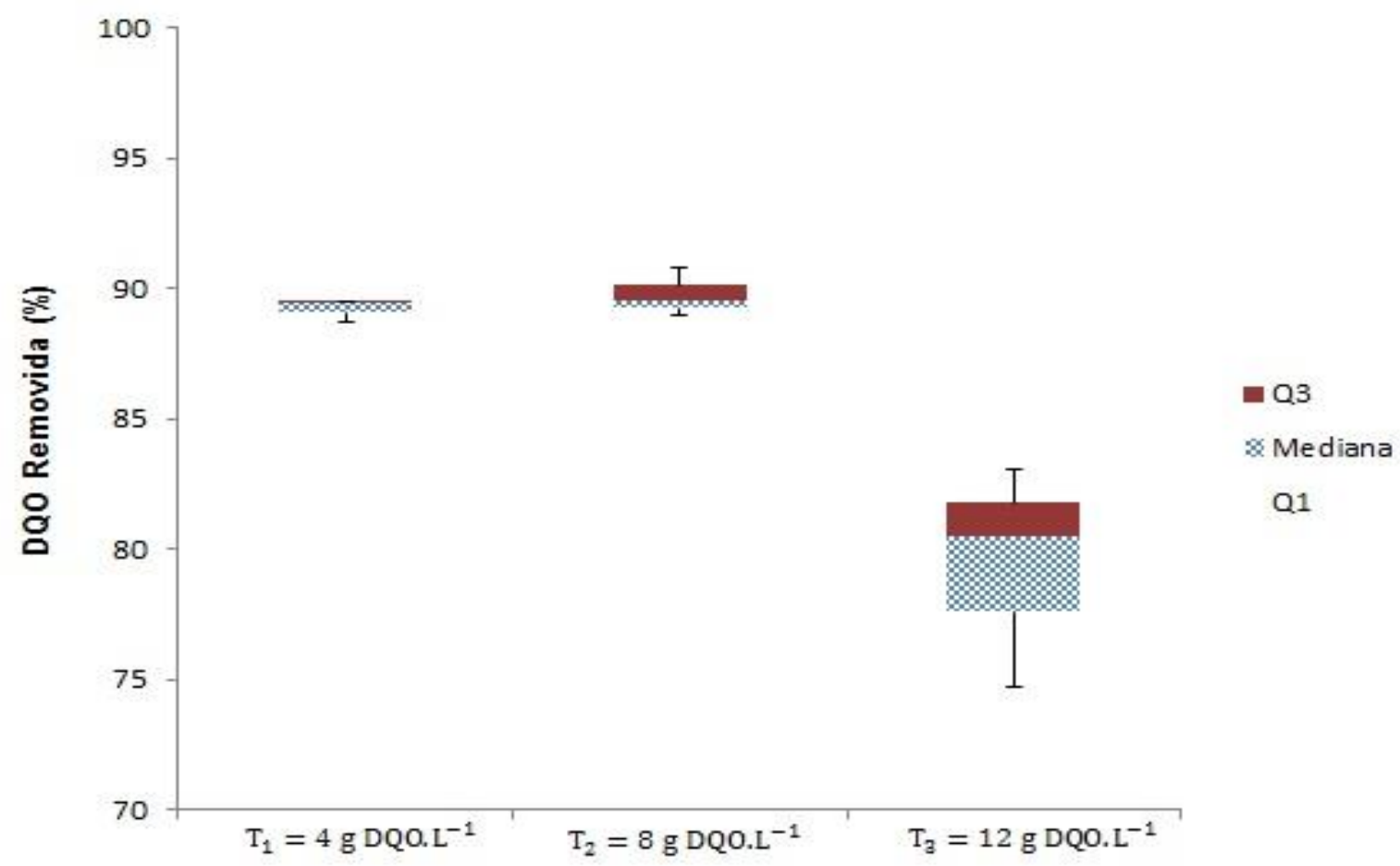

Fonte: Autores. 
Figura 5: Produção acumulada de metano ao longo do tempo de biodegradação.

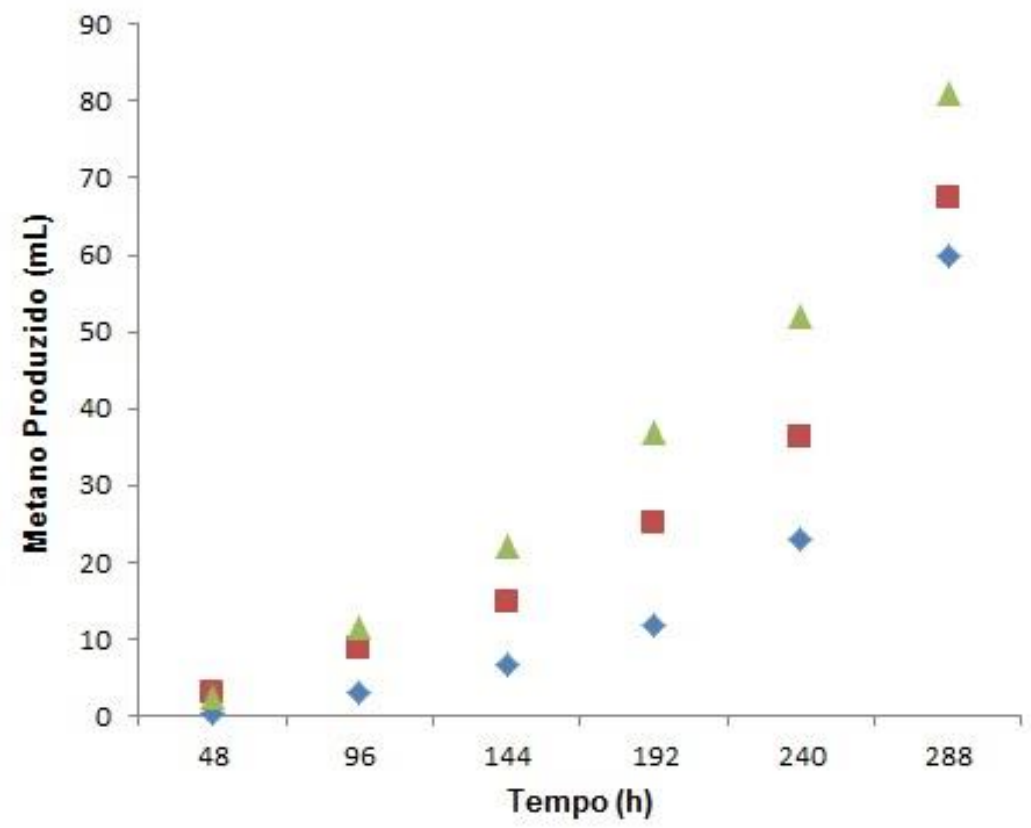

- $\mathrm{T}_{1}=4 \mathrm{~g} \mathrm{O}_{2} \cdot \mathrm{L}^{-1}$

- $\mathrm{T}_{2}=8 \mathrm{~g} \mathrm{O}_{2} \cdot \mathrm{L}^{-1}$

$\triangle \mathrm{T}_{3}=12 \mathrm{~g} \mathrm{O}_{2} \cdot \mathrm{L}^{-1}$

Fonte: Autores.

Tabela 3: Rendimento de metano em relação ao metano teórico e taxa de produção de metano.

\begin{tabular}{cccc}
\hline Tratamento & $\mathbf{V}_{\mathbf{C H} 4}(\mathbf{m L})$ & $\mathbf{R}_{\mathbf{C H} 4}(\%)$ & $\mathbf{T P}_{\mathbf{C H} 4}\left(\mathbf{m L}\right.$ de $\left.\mathbf{C H}_{\mathbf{4} \cdot \mathbf{~ g}^{-1} \mathbf{d e ~} \mathbf{D Q O}} \mathbf{O}_{\text {rem }}\right)$ \\
\hline $\mathbf{T}_{\mathbf{1}}$ & 59,9 & 42,5 & 102,0 \\
$\mathbf{T}_{\mathbf{2}}$ & 67,3 & 29,8 & 70,0 \\
$\mathbf{T}_{\mathbf{3}}$ & 81,0 & 25,7 & 75,3
\end{tabular}

V $\mathrm{TP}_{\mathrm{CH} 4}$ : Taxa de produção de metano.

Fonte: Autores.

\section{CONCLUSÃO}

Conclui-se que todos os tratamentos demonstraram potencial para a biodegradação, apresentando remoção de matéria orgânica acima de $65 \%$ durante todo o tempo de degradação.

A avaliação das condições ambientais mostrou durante os ensaios que os tratamentos não ofereceram capacidade de tamponamento ao sistema, indicando que em reatores anaeróbios deve-se haver correção de pH com a adição de alcalinizantes.

Dentre os tratamentos, $\mathrm{T}_{1}$ apresentou o maior rendimento de metano (42,5\%), bem como a maior taxa de produção de metano (102 $\mathrm{mL}$ de $\mathrm{CH}_{4} \cdot \mathrm{g}^{-1}$ de DQOrem).

\section{AGRADECIMENTOS}

Agradecemos, primeiramente, ao Ministério da Educação (MEC)/Coordenação de aperfeiçoamento de Pessoal de Nível Superior (CAPES)/Programa de Educação Tutorial (PET) Conexões de Saberes: Saneamento Ambiental pelo incentivo financeiro e manutenção das bolsas. Á NIAGRO pela parceria e apoio, fornecendo o material de estudo que permitiu o desenvolvimento dessa pesquisa, à EMBRAPA Semiárido, principalmente ao Laboratório de Química Ambiental por tornar possível a realização de análises específicas que contribuíram para o enriquecimento do trabalho e, por fim, à Universidade Federal do Vale do São Francisco UNIVASF e o Laboratório de Engenharia Ambiental - LEA pela estrutura e recursos 
disponibilizados que tornaram realmente possível a execução da pesquisa.

\section{REFERÊNCIAS}

AMARAL, M. C. S.; FERREIRA, C. F. A.; LANGE, L. C.; AQUINO, S. F. Avaliação da biodegradabilidade anaeróbia de lixiviados de aterros sanitários. Revista Engenharia Sanitária e Ambiental, Rio de Janeiro, v. 13, n.1, p. 38-45, 2008.

AMORIM, M. C. C.; SILVA, P. T de S.; GAVAZZA, S.; NUNES, A. C. D.; SANTOS, P. T. T.; MOTTA SOBRINHO, M. A. Sewage sludge, goat rumen and cattle rumen as inoculum for the anaerobic segradation of Manipueira. In: SIMPÓSIO LATINO-AMERICANO DE DIGESTÃO ANAERÓBICA, 11., 2014, Havana. Anais... Havana, Cuba: CPATSA, 2014, p. 12.

AMORIM, S. M; KATO, M. T; FLORENCIO, L.; GAVAZZA, S. Influence of redox mediators and electron donors on the anaerobic removal of color and chemical oxygen demand from textile effluent. Clean - Soil, Air, Water, v. 41, p. 928-933, 2013.

AQUINO, S.; CHERNICHARO, C. A. L.; FORESTI, E.; SANTOS, M. L. F.; MONTEGGIA, L. O. Metodologias para determinação da atividade metanogênica específica (AME) em lodos anaeróbios. Revista de Engenharia Sanitária e Ambiental, Rio de Janeiro, v. 12, n. 2, p.192-201, 2007.

BARROS, E. S. C. Remoção de carga orgânica do efluente da agroindústria de acerola (Malphigia Emarginata D.C.) em reator UASB. 2017. $59 \mathrm{f}$. Monografia (Graduação em Engenharia Agrícola e Ambiental) - Universidade Federal do Vale do São Francisco, Juazeiro, 2017.

BERTOLINO S. M.; CARVALHO, C. F.; AQUINO, S.F. Caracterização e biodegradabilidade aeróbia e anaeróbia dos esgotos produzidos em campus universitário. Engenharia Sanitária e Ambiental, Rio de Janeiro, v. 13, n. 3, p. 271-277, 2008.

CALGARO, M.; BRAGA, M. B. Coleção plantar: a cultura da acerola. 3. ed. rev. ampl. - Brasília, DF: Embrapa, 2012. p. 144. Disponível em: <https://ainfo.cnptia.embrapa.br/digital/bitstream/item/1 28278/1/PLANTAR-Acerola-ed03-2012.pdf>. Acesso: 04 abr. 2018.

CARRINGTON, C.M.S.; KING, R.A.G. Fruit development and ripening in Barbados cherry, Malphigia emarginata DC. Scientia Horticulturae, Amsterdam, v. 92, n. 1, p. 1-7, jan. 2002.

CARVALHO, R.A.; FERREIRA, C.A.P.; NASCIMENTO JÚNIOR, J.D.B.; MENEZES, A.J.E.A.; SUZUKI, E.;
SASAKI, G. Análise econômica da produção de acerola no Município de Tomé-Açu, Pará. Belém: Embrapa Amazônica Oriental, Documento 49, 2000. Disponível em: <https://www.infoteca.cnptia.embrapa.br/bitstream/doc/ 377928/1/OrientalDoc49.pdf Acesso: 10 jun. 2018. ÇELIK, I.; DEMIRER, G. N. Biogas production from pistachio (Pistacia vera L.) processing waste. Biocatalysis and Agricultural Biotechnology, v. 4, n. 4, p. 767-772, 2015.

CHERNICHARO, C. A. L. Princípios do tratamento biológico de águas residuárias: reatores anaeróbios. 2. ed. Belo Horizonte: Editora UFMG, 2007. 31 p. CORRÊA, C.V.; GOUVEIA, A.M.S.; MARTINS, B.N.M.; JORGE, L.G.; LANNA, N.B.L.; TAVARES, A.E.B.; MENDONÇA, V.Z.; EVANGELISTA, R.M. Influence of ripening stages on physicochemical characteristics of acerola fruits. Revista de Ciências Agrárias, Lisboa, v. 40, n. 4, p. 130-139, 2017.

COSTA, E. S. Proposta de protocolo para projeto de engenharia ambiental de reatores anaeróbios de fluxo ascendente com manta de lodo. 2009. Dissertação (Mestrado em Engenharia Ambiental) Universidade do Estado do Rio de Janeiro, Rio de Janeiro, 2009.

FLORÊNCIO, L. The fate of metanol in anaerobic bioreactors. 1994. Thesis (Ph.D) - Wageningen Agricultural University, Wageningen, The Netherlands, 1994.

GODOY, R.C.B.; MATOS, E.L.S.; AMORIM, T.S.; NETO, M.A.S; RITZINGER, R.; WASZCZYNSKY, N. Avaliação de genótipos e variedades de acerola para consumo in natura e para elaboração de doces. Boletim do Centro de Pesquisa e Processamento de Alimentos, v. 26, n. 2, p. 197-204, dez. 2008.

INSTITUTO BRASILEIRO DE GEOGRAFIA E ESTATíSTICA (IBGE). Censo Agropecuário, 2017. Disponível em: <https://censoagro2017.ibge.gov.br/templates/censo_a gro/resultadosagro/

agricultura. $h t m \mid$ ?localidade $=0 \&$ tema $=76215>$. Acesso: 22 out. 2018.

JERÔNIMO, C. E. M. Gestão agroindustrial: pontos críticos de controle ambiental no beneficiamento de frutas. Revista de Administração de Roraima - RARR, ed. 2, v. 2, p. 70-77, 2012.

LACERDA, M.A.D.; LACERDA, R.D.O. Cluster da fruticultura no Pólo Petrolina/Juazeiro. Revista de Biologia e Ciências da Terra, v. 4, n. 1, 1ํ semestre 2004.

LOUSADA JUNIOR, J. E.; NEIVA, J. N. N.; RODRIGUEZ, N. M.; PIMENTEL, J. C. M. P.; LÔBO, R. 
N. B. Consumo e digestibilidade de subprodutos do processamento de frutas em ovinos. Revista Brasileira de Zootecnia, v. 34, p. 659-669, 2005.

MAGALHÃES, D.S.; RUFINI, J.C.M.; ALBURQUERQUE, A.S.; VIOL, R.E.; FAGUNDES, M.C.P.; MENEZES, T.P. Genetic diversity among accessions of acerola based on the quality of fruits. Comunicata Scientiae, v. 9, n. 2, p. 133-141, 2018.

METCALF \& EDDY. Wastewater engineering: treatment, disposal and reuse. 4 ed. New York: McGrawHillBook, 2003. p. 1771.

MONTEFUSCO, N.; BARROS, E.; MATTOS, R.; SILVA, W.; AMORIM, M. Caracterização e potencial geração de metano por efluente da agroindústria da acerola. Gestão Integrada de Resíduos: Universidade \& Comunidade, Campina Grande, UFCG, v. 3, p. 122125, 2018. Ebook. ISBN 978-85-60307-31-9. Disponível em:

<https://www.researchgate.net/profile/Paulo_Roberto_F rancisco/publication/322901570_Gestao_integrada_de_ residuos_universidade_comunidade_v3/links/5a74f704 a6fdccbb3c058f2e/Gestao-integrada-de-residuos- universidade-comunidade-v3.pdf>. Acesso: 18 out. 2018.

SOBRINHO, I.S.B. Propriedades nutricionais e funcionais de resíduos de abacaxi, acerola e cajá oriundos da indústria produtora de polpas. Dissertação (Mestrado em Ciências Ambientais) Centro de Ensino, Pesquisa e Extensão Socioambiental, Universidade Estadual do Sudoeste da Bahia, Itapetinga, 2014.

SOUZA, F.F.; DEON, M.D.; CASTRO, J.M.C; CALGARO, M. Contribuições das pesquisas realizadas na Embrapa Semiárido para a cultura da aceroleira. Petrolina: Embrapa Semiárido, 2017. 28 p. (Embrapa Semiárido. Documentos, 282). Disponível em: $<$ https://www.infoteca.cnptia.embrapa.br/infoteca/bitstre am/doc/1088295/1/SDC282.pdf>. Acesso: 10 jun. 2018.

WEBER, M. I. Avaliação da eficiência de um reator anaeróbio de leito fluidizado para tratamento de resíduos líquidos da indústria de refrigerantes. 2006. 166 f. Dissertação (Mestrado em Engenharia de Recursos Hídricos e Ambiental) - Universidade Federal do Paraná, Curitiba, 2006. 